\title{
Research on Microstructures and Mechanical Properties of Mg-Gd-Y-Sr-Zr Alloy
}

\author{
Lei-lei CHEN ${ }^{1, a}$, Quan-an LI ${ }^{1,2, b}$, Jun Chen ${ }^{1}$, Qing zhang ${ }^{1}$ and Xing-yuan \\ $\mathrm{ZHANG}^{1}$
}

\author{
${ }^{1}$ School of Materials Science and Engineering, Henan University of Science and Technology, \\ Luoyang 471023, China \\ ${ }^{2}$ Collaborative Innovation Center of Nonferrous Metals, Henan Province, Luoyang, 471023, China \\ aemail: cll19880623@163.com, bemail: q-ali@163.com
}

Keywords: Mg-Gd-Y-Sr-Zr alloy, mechanical properties, microstructures.

\begin{abstract}
The microstructures and mechanical properties of Mg-Gd-Y-Sr-Zr alloy was investigated by means of optical microscopy, scanning electron microscopy (SEM), X-ray diffraction (XRD) and tensile tests. The as-cast alloy contains a microstructure consisting of $\alpha-\mathrm{Mg}$ matrix, $\mathrm{Mg}_{5} \mathrm{Gd}$ phase, $\mathrm{Mg}_{24} \mathrm{Y}_{5}$ phase and $\mathrm{Mg}_{17} \mathrm{Sr}_{2}$. As the temperature increases, the tensile strength of the alloy decreases. However, the elongation increases with increasing the temperature.
\end{abstract}

\section{Introduction}

At present, magnesium alloys are the lightest structural alloys commercially available and have great potential for applications in automobile industry, 3C (Computer, Communication, Consumer Electronic) and electron industry [1,2]. However, the creep properties of magnesium alloys are limited by their low melting point which can vary depending on the alloying content $[3,4]$. Thus, developing a new kind of magnesium alloys with high mechanical performance is a significant issue $[5,6]$.

Rokhlin [7] and He Shangming [8] have developed $\mathrm{Mg}-\mathrm{Gd}-\mathrm{Y}-\mathrm{Zr}$ alloys which show higher strength at both room and elevated temperature and better creep resistance than WE54 and QE22. And they also have investigated the relationship between mechanical properties and microstructures of these high gadolinium-containing magnesium alloys. It was reported that the addition of $\mathrm{Ca}, \mathrm{Sr}$ and rare earth(RE) elements is effective to improve the performance of magnesium alloy[9]. Due to the above-mentioned reasons, the present investigation aims to study the microstructures and mechanical properties of Mg-Gd-Y-Sr-Zr alloy.

\section{Experimental Procedures}

Mg-30Gd (wt.\%), Mg-25Y (wt.\%), Mg-20Sr (wt.\% ) and Mg-25Zr (wt.\%) master alloys were made first by melting high purity $\mathrm{Mg}(\mathrm{N} 99.95 \%), \mathrm{Gd}(\mathrm{N} 99.9 \%)$ and $\mathrm{Y}(\mathrm{N} 99.9 \%)$ in a vacuum medium- frequency induction furnace under an argon atmosphere. Then, the $\mathrm{Mg}-5 \mathrm{Gd}-3 \mathrm{Y}-2 \mathrm{Sr}-0.5 \mathrm{Zr}$ alloy ingots were prepared from high purity $\mathrm{Mg}$ (99.95\%), the Mg-30Gd (wt.\%), Mg-25Y (wt.\%), Mg-20Sr (wt.\% )and Mg-25Zr (wt.\%) master alloys in a medium- frequency induction furnace with a graphite $(99.99 \%)$ crucible under a mixed atmosphere of $\mathrm{CO}_{2}$ and SF6 with the ratio of 100:1. The chemical composition of the experimental alloys is listed Table 1.

Table 1. Chemical composition of alloys (mass fraction, \%)

\begin{tabular}{cccccc}
\hline Alloy & $\mathrm{Gd}$ & $\mathrm{Y}$ & $\mathrm{Sr}$ & $\mathrm{Zr}$ & $\mathrm{Mg}$ \\
\hline Mg-Gd-Y-Sr-Zr & 5.0 & 3.0 & 2.0 & 0.5 & Bal. \\
\hline
\end{tabular}

Before the melting started, all the materials and the permanent metallic mold should be dried at $200^{\circ} \mathrm{C}$ for 1-2 hours. Firstly, he high purity $\mathrm{Mg}$ were heated to melt. When the temperature rose to 
720-740 ${ }^{\circ} \mathrm{C}$, the $\mathrm{Mg}-30 \mathrm{Gd}$ (wt.\%), Mg-25Y (wt.\%) and Mg-20Sr (wt.\% ) were added into the molten metal. After all the alloy melted ,Mg-25Zr (wt.\%) master alloys were putted into. Then, the melt was held at $740^{\circ} \mathrm{C}$ for $5 \mathrm{~min}$ to obtain a uniform alloy, which was stirred at the same time. Finally, when the temperature was reduced to $710-720^{\circ} \mathrm{C}$, the melt was slowly poured into the permanent metallic mold which was preheated to $200 \sim 250^{\circ} \mathrm{C}$.

After casting, the solution treatment and aging were respectively at $510 \mathrm{C} \times 6 \mathrm{~h}$ and $225 \mathrm{C} \times 12 \mathrm{~h}$. Tensile tests were performed by using a SHIMADZU AG-I 250kN precision universal material test machine at room temperature $(\mathrm{RT}), 200 \mathrm{C}, 250 \mathrm{C}$ and $300 \mathrm{C}$ respectively. For the elevated temperature tensile specimens, they were held for 5 minutes at their corresponding temperatures. And at least three bars were used for each test. All the specimens were etched in a 4 vol.\% natal. The microstructures were observed using optical microscopy (OM), D8ADVANCE type X-ray diffraction analysis (XRD) and JSM 5610LV scanning electron microscopy (SEM), separately.

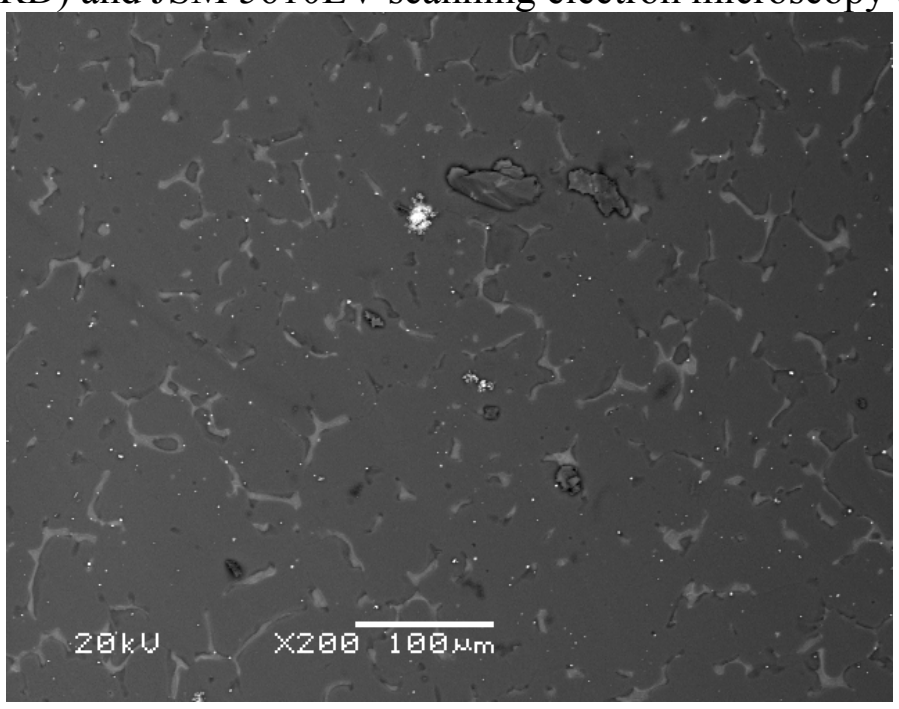

Fig. 1. SEM image of as-cast $\mathrm{Mg}-5 \mathrm{Gd}-3 \mathrm{Y}-2 \mathrm{Sr}-0.5 \mathrm{Zr}$ alloy

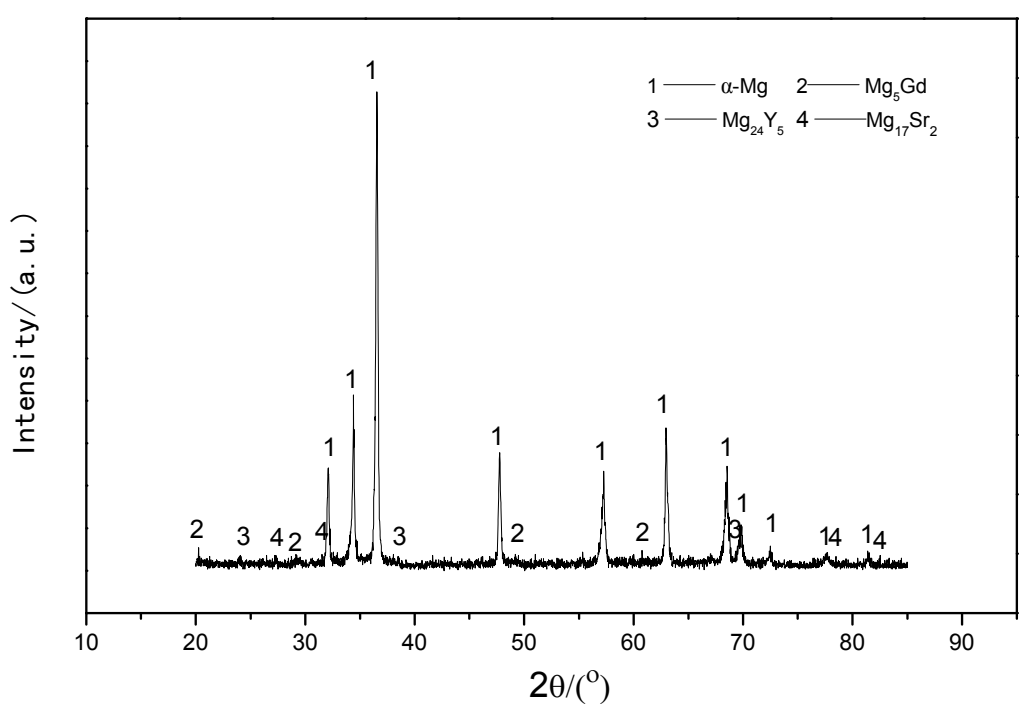

Fig. 2. XRD pattern of as-cast $\mathrm{Mg}-5 \mathrm{Gd}-3 \mathrm{Y}-2 \mathrm{Sr}-0.5 \mathrm{Zr}$ alloy 


\section{Results and Discussion}

The SEM image of as-cast $\mathrm{Mg}-5 \mathrm{Gd}-3 \mathrm{Y}-2 \mathrm{Sr}-0.5 \mathrm{Zr}$ alloy is shown in Fig. 1. In the SEM image, it was observed that one phase solid solution with the white net-work of second phase which is mostly disposed between the dendrite branches of $\alpha-\mathrm{Mg}$ solid solution, and there are many white petal-like $\mathrm{Zr}$-rich regions were diffuse in the $\alpha-\mathrm{Mg}$ matrix. The average grain size is very fine. Fig. 2 shows the phase compositions of the as-cast alloy by XRD analysis. It indicates that $\mathrm{Mg}-5 \mathrm{Gd}-3 \mathrm{Y}-2 \mathrm{Sr}-0.5 \mathrm{Zr}$ alloy mainly consists of $\alpha-\mathrm{Mg}$ solid solution, $\mathrm{Mg}_{5} \mathrm{Gd}, \mathrm{Mg}_{24} \mathrm{Y}_{5}$ and $\mathrm{Mg}_{17} \mathrm{Sr}_{2}$ eutectic compounds.

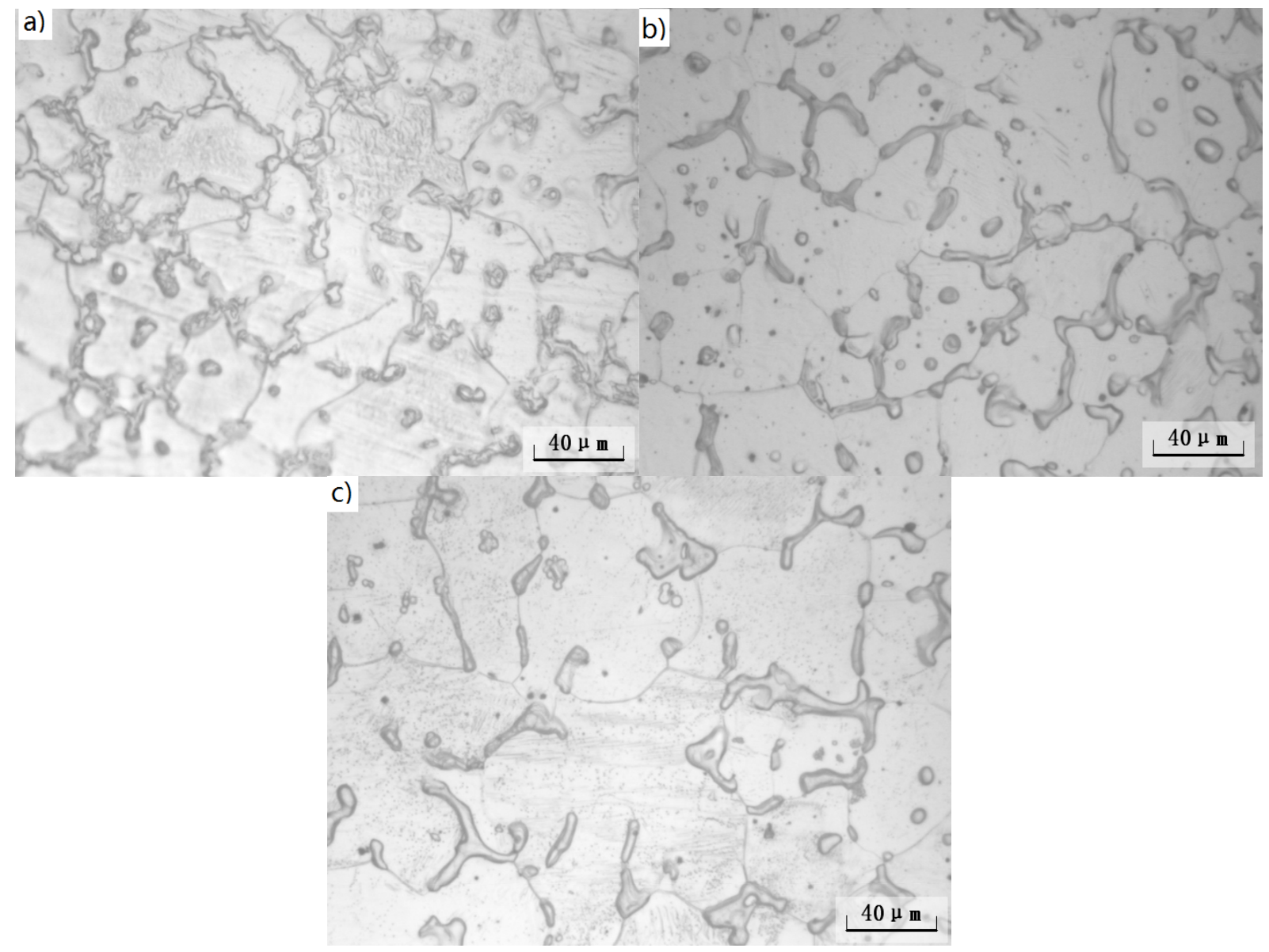

Fig. 3.The microstructures of $\mathrm{Mg}-5 \mathrm{Gd}-3 \mathrm{Y}-2 \mathrm{Sr}-0.5 \mathrm{Zr}$ alloy

a)as-cast b)solid solution c)aging treatment

The microstructure evolutions of $\mathrm{Mg}-5 \mathrm{Gd}-3 \mathrm{Y}-0.5 \mathrm{Zr}$ alloy with different treatment are list in Fig. 3. It was found that some of the precipitate dissolve into the matrix after solution treatment, but the most of the precipitate do not dissolve into the $\alpha-\mathrm{Mg}$ matrix. After aging treatment, compare to the as-cast alloy the microstructures become more uniform.

Table 2. The tensile properties of $\mathrm{Mg}-5 \mathrm{Gd}-3 \mathrm{Y}-2 \mathrm{Sr}-0.5 \mathrm{Zr}$ alloy

\begin{tabular}{cccc}
\hline Temperature & $\begin{array}{c}\text { Tensile Strength } \\
{[\mathrm{MPa}]}\end{array}$ & $\begin{array}{c}\text { Elongation } \\
{[\%]}\end{array}$ \\
\hline \multirow{2}{*}{$200 \mathrm{C}$} & RT & 190.7 & 2.83 \\
& & 186.0 & 3.21 \\
& $250 \mathrm{C}$ & 185.0 & 5.05 \\
& 300C & 154.3 & 7.09 \\
\hline
\end{tabular}


The tensile properties, including tensile strength and elongation of the aging treatment experimental alloys are listed in Table 2. It is observed from Table 2 that the tensile strength of the $\mathrm{Mg}-5 \mathrm{Gd}-3 \mathrm{Y}-2 \mathrm{Sr}-0.5 \mathrm{Zr}$ alloy decreases with the increasing of the temperature. However, as the temperature increases, the elongation of the aging treatment experimental alloys increases.

\section{Conclusions}

1) The as-cast $\mathrm{Mg}-5 \mathrm{Gd}-3 \mathrm{Y}-0.5 \mathrm{Zr}$ alloy mainly consists of $\alpha-\mathrm{Mg}$ solid solution, $\mathrm{Mg}_{5} \mathrm{Gd}, \mathrm{Mg}_{24} \mathrm{Y}_{5}$ and $\mathrm{Mg}_{17} \mathrm{Sr}_{2}$ phases.

2) With the increase of the temperature, the tensile strength of the aging treatment experimental alloys decreases and the elongation increases.

\section{Acknowledgement}

In this paper, the research was sponsored by the National Natural Science Foundation of China (51171059),Basic and Frontier Technologies Research Plan of Henan Province 102300410018) and by Program for Innovative Research Team (in Science and Technology) in University of Henan Province(2012IRTSTHN008).

\section{References}

[1]Mingbo Yang, Fusheng Pan and Liang Cheng. Effects of Minor Sr on As-Cast Microstructure and Mechanical Properties of ZA84 Magnesium Alloy[J]. Journal of Materials Engineering and Performance, 2010, 19(7): 1043-1050.

[2] Aghion E, Bronfin B, Eliezer D. The role of the magnesium industry in protecting the environment[J]. Journal of Materials Processing Technology, 2001, 117(3): 381-385.

[3] Zhanhui Wang, Wenbo Du, Xudong Wang, et al. Microstructure evolution of Mg-9Gd $-2 \mathrm{Er}-0.4 \mathrm{Zr}$ alloy during solid solution treatment[J]. Transactions of Nonferrous Metals Society of China, 2013, 23(3): 593-598.

[4] Bayani, Hossein. Effect of rare earth elements addition on thermal fatigue behaviors of AZ91 magnesium alloy[J]. Journal of Rare Earths, 2009, 27(2): 255-258.

[5] Gang Chen, Xiao-dong Peng, Pei-geng Fan, et al. Effects of Sr and Y on microstructure and corrosion resistance of AZ31 magnesium alloy[J]. Transactions of Nonferrous Metals Society of China, 2011, 21:725-731.

[6] Mingbo Yang, Caiyuan Qin, Fusheng Pan, et al. Comparison of effects of cerium, yttrium and gadolinium additions on as-cast microstructure and mechanical properties of $\mathrm{Mg}-3 \mathrm{Sn}-1 \mathrm{Mn}$ magnesium alloy[J]. Journal of Rare Earth, 2011,29(6): 550-557.

[7] L.L. Rokhlin, Advance Light Alloys and Composites, in: Proceedings of NATO Advanced Study Institute, Kluwer, 1998, pp. 443.

[8] S.M. He, X.Q. Zeng, L.M. Peng, et al. Microstructure and strengthening mechanism of high strength Mg-10Gd-2Y-0.5Zr alloy[J]. Journal of Alloys and Compounds, 2007, 427: 316-323.

[9] SHANG L, JUNG I H, YUE S, VERMA R, ESSADIQI E. An investigation of formation of second phases in microalloyed AZ31 Mg alloys with $\mathrm{Ca}, \mathrm{Sr}$ and $\mathrm{Ce}[\mathrm{J}]$. Journal of Alloys and Compounds,2010, 492(1-2): 173-183. 